\title{
Enhancing Intrinsic Motivation to Learn in Adults: Empowering ESL Students
}

\author{
Hamid Hassan ${ }^{1}$, Nisrin A Hariri ${ }^{1} \&$ Khushnoor Khan ${ }^{2}$ \\ ${ }^{1}$ English Language Institute King Abdulaziz University Jeddah, 80200, Saudi Arabia \\ ${ }^{2}$ Faculty of Science, Department of Statistics, King Abdulaziz University, Jeddah, 21589, Saudi Arabia \\ Correspondence: Khushnoor Khan, Faculty of Science, Department of Statistics, King Abdulaziz University, \\ Jeddah, 21589, Saudi Arabia. E-mail: khushnoorkhan64@gmail.com
}

Received: October 2, 2019 Accepted: November 4, 2019 Online Published: December 15, 2019

doi:10.5539/ijel.v10n1p81 URL: https://doi.org/10.5539/ijel.v10n1p81

\begin{abstract}
The apex in the acquisition of a second language is dependent upon motivation and attitude coupled and nurtured in a formal language learning milieu. Adult learners of English as a Second Language (ESL) can be motivated intrinsically in numerous ways. The types of motivation, whether intrinsic or extrinsic, are not categorically different; instead, they lie in the same transition of self-determination. Direction relative to one's surroundings serves as a long-range goal and sustains students' motivation to learn a second language. The decision to learn in many cases comes from within. Internalizing the reasons for language learning are internalized, students feel more insistency, comfort, and ease. Teachers should strive to promote positive self-talk and guided self-evaluation within students, along with emphasizing mastery of specific goals. Setting higher but attainable goals for an ESL learner activates endeavors and influences performance. Instructors should reveal intrinsic attractions latent in every subject as the appeal-laden lessons have a high quality to attract most students. Knowing and assimilating a target language's culture contributes positively to a learner's development. An ESL classroom should be a welcoming, positive place where communication needs are met and where language anxiety is minimum, and the student seems to enjoy many of the practice opportunities. Instructors should create a stimulating, supportive ambiance that fosters self-esteem and interest in learning. Repeated readings in small groups develop expertise in verbal skills. Further, it encourages curiosity, which is of paramount significance for creating motivation and making ESL learning fun. Present research will be a harbinger of further research in Middle Eastern educational milieu and will open new vistas for academicians and practitioners involved in teaching as a foreign language.
\end{abstract}

Keywords: extrinsic motivation, second language, Middle East, second language

\section{Introduction}

Extrinsic motivation is generally prominent in Foreign Language (FL) context. The results concerning the success of Second Language (L2) acquisition are still under investigation because, although some studies confirm the validity of intrinsic motivation to attain success in the acquisition of an L2, others support the significance of extrinsic motivation as well as the existence of some other alignments.

The socio-educational model of L2 acquisition presented by Gardner (1985) suggests that formal language learning takes place in the classroom, and motivation is one of the most important variables in second language acquisition. It is further proposed that coordination of mental processes and attitude towards learning constitute an incorporated approach that improves language learning. It has been studied closely that both formal and informal language-learning contexts provide linguistic and non-linguistic outcomes. Linguistic outcomes refer to an augmentation of knowledge, fluency, and familiarity of the target language (Gardner, 1985; Gardner, Trembly, \& Masgoret, 1997; Trembly \& Gardner, 1995).

This paper focuses on delineating how adult learners of English as a Second Language (ESL) can be motivated. There are two general types of motivation- intrinsic and extrinsic, and these types are not categorically different; instead, they lie along a continuum of self-determination. Intrinsic motivation generally refers to motivation to engage in an activity because that exercise is enjoyable and satisfying. Deci and Ryan (1985) hypothesize that when people are free to choose to perform an activity, they will seek new situations where they can rise to the challenges that the activity presents, and resultantly, they develop a sense of competence in their abilities. In 
contrast to intrinsically motivated behaviors, extrinsically motivated behaviors are actions that can be carried out to achieve some instrumental end, such as earning a reward or avoiding a punishment Noels and Pelletier (2000).

The second object of this discourse is to direct attention to the empirical literature reflecting the role played by intrinsic motivation in second language acquisition. Intrinsic motivation is an inherent tendency to seek out the challenges and novelty, to exercise one's capacities, and to endeavor to extend, to explore, and to learn. It is a natural inclination towards assimilation, mastery, spontaneous interest, and exploration that is vital for social and cognitive development. It is an innate tendency; however, the maintenance and enhancement of this inherent propensity require supportive conditions. It represents a principal source of enjoyment and vitality throughout life. Further, in the real world, it is highly valued because it is productive Ryan and Deci (2000).

The third object of this study stems from the facts that as the authors have long experiences of teaching English to Saudi students and are aware that Saudi student lack intrinsic motivation but the same has not been studied in previous researches. The present study will open new vista and provide a solid foundation for the researchers and practitioners in the Middle Eastern region to probe into the factors that enhance extrinsic motivation of Arabic speaking students keeping in view their cultural sensitivities.

\section{Why Do Adults Learn ESL?}

Intrinsic motivation is associated with psychological consequences and results that are related to the educational domains. These include particularly sports, leisure, and adult learning activities (Vallerand \& Pelletier, 1993). Clement and Kruidenier's study (1985) reveals that students are more prone to learn ESL for friendship, travel, understanding, prestige, knowledge, respect, and in response to the external stimulus, meaning that their orientation is context-based. In another research study, some of the other motives to study ESL were to use the internet or to understand English songs (Belmerchi \& Hummel, 1998).

Orientation is believed to be associated with the predictors of students' motivation, whereas inspiration has been seen as a combination of intensity and stimulation that corresponds to the extended effort and learners' goals. Intellectual thought to produce an idea for change is a long-range goal that sustains students' motivation to learn an SL. Researchers suggest that these long-range goals break up into clusters of direction of thought, which are context-dependent. Thus, instrumental orientation is related to practical acquisition (Gardner, 1985), whereas Clement and Kruidenier (1985) associate it with career and school advancement motives. According to Belmerchi and Hummel (1998), the most significant orientations to learn ESL are travel, understanding/school, career (instrumental), and friendship, understanding (general).

Clement and Kruidenier (1985) suggested prestige and knowledge as significant factors for learning ESL. Belmerchi and Hummel (1998) have included prestige under self-understanding orientation, whereas knowledge emerges under general orientation. Exclusively, travel has been linked with an underlying area of learners' desire to make friends because the researchers believe that learning ESL in order to travel stands on its own as a potent orientation irrespective of being instrumental or integrated. Traveling to the USA or the UK for studying English is an acceptable goal that has been identified under a proper motivational orientation. Oxford and Shearin (1994) classified it as "an assimilative motivation", which is the heightened form of intrinsic motivation in which a person gives up his or her own culture to assimilate into the target culture. Kyriacou and Kobori (1998) have investigated that the fact that English is an international language can help students in their advanced study and future career. They found learners' propensity for advanced study and career-making as significant reasons for influencing a student's motivation to learn English. They also suggested that the most critical influences on pupils' motivation to learn English and on student teachers' motivation to become a teacher of English seem to be generally applicable to a wide variety of countries.

On the other hand, members of the working class may feel more motivated to learn ESL when they realize that they will be able to talk to others or their children's school teachers (Payne, 2000). Prospective workers know that if they learn English, they will have ample opportunities for work. That is why some of them tend to write down the expressions they hear in the classroom as a few of the sayings they hear in the corporate world may be of little immediate use to them. The most significant advancement is for their personal growth, to help them better assimilate in a bilingual society (Gray, 2001). Teachers can help students heighten their motivation by demonstrating that ESL can be an exciting mental challenge, a career enhancer, a vehicle to cultural awareness and friendship, and a key to world peace (Oxford \& Shearin, 1994).

Gottfried (1990) found a significant positive correlation between intrinsic motivation and academic performance. Consequently, intrinsically motivated students are more likely to stay in school. Research shows that those who experience success are among the most motivated students. Thus, motivation plays a duel role. It serves as a result of success as well as a cause. In ESL, encouragement through success and accomplishment is far more 
helpful than encouraging development through errors and corrections. A learner who is going to guess may make mistakes while communicating in an SL, and hence, if one is encouraged to spend more time studying, they should be successful (Yule, 1996).

\section{Motivation and Self: Autonomous Learning}

Motivation is a potent force that corresponds to the expended effort and learner's goals (Belmerchi \& Hummel, 1998). This power results from within, consisting of conviction, desire, attitude, and effort of the learner. Increasing motivation requires focusing on a student's thoughts, feelings, and decisions. Usually, the decision to learn comes from within if the learners decide to grow academically and professionally (Wan, 2001). Students feel more comfort and perseverance if the reasons for language learning are internalized Noels and Pelletier (2000). For example, when a child reads a book for the inherent pleasure of doing so, s/he is intrinsically motivated for that activity. Intrinsically motivated behavior represents the prototype of self-determination - that emanates from the self and is fully endorsed. That is why, when behavior is self-determined, the person perceives that the center of causality is internal to his or her self, whereas when it is controlled, the perceived center of causality is external to the self (Deci, Vallerand, Pelletier, \& Ryan, 1991). In self-determination theory, internalization is a motivated process. Therefore, the teachers should motivate learners by making them believe that advancement in learning is possible through the students' efforts. Extrinsic rewards provided by the teacher are part of the SL instructional design, but the teacher can also urge the students to develop their intrinsic rewards through positive self-talk and guided self-evaluation. A teacher can help students build their intrinsic reward system by emphasizing mastery of specific goals that do not involve comparison with other students. The teacher can thus enable students to have an increased sense of self-efficacy, whereby they attribute the outcome of their study to their efforts rather than to the beliefs of teachers or other students. Higher self-efficacy increases motivation to continue learning the SL. Extrinsically motivated behaviors are instrumental because they are performed with the belief that the consequences of avoiding corrective action determine how a person function. Gronlnick and Ryan (1987) found that autonomous motivation for doing school work, in general, leads to more significant concept learning and fosters better memory compared to those who possess less autonomous motivation. Similar results were evident in the experiment done by Benware and Deci (1984). The college students who learned text material in order to put it to use reported more intrinsic motivation for learning and showed greater conceptual understanding than did students who learned the material in order to be tested.

A close link exists between attention and motivation as motivation refers to the direction of focusing on effort (Taylor \& Adelman, 1999). When a person attends to a task for an extended period of time, s/he is said to be motivated. The activities presented by an ESL teacher should provide an impetus for anticipation and expectancy. Higher expectancies tend to motivate students to perform assigned activities. According to Bandura (1977), an essential expectancy is self-efficacy. In language learning, the term self-efficacy is synonymous with self-confidence, which is the most important determinant of motivation to learn an SL. Deci et al. (1991) suggest that valuing, development, competence, relatedness, and autonomy are significant for the evolvement of motivation and self-determination. Therefore, promoting greater self-determination, that is, a great sense of choice, more self-initiation of behavior, and greater personal responsibility should be the aim of an ESL teacher as it will foster a developmental goal, which has an outcome in the form of creativity. Creativity depends in large part on intrinsic motivation and reward, while extrinsic motivators can undermine both.

According to Deci and Ryan (1985), letting people choose freely to perform an activity helps them create new situations for achieving a goal. Consequently, learners develop a sense of competence with the freedom to choose. There is a positive relationship between the students' perception of parental encouragement and motivation to learn a second language (Gardner \& Masgoret, 1999). Research reveals that parents' involvement with their children may lead to greater motivation and self-determination, especially when accompanied by free support. Research on the effects of environmental events on intrinsic motivation tends to focus on the issue of autonomy versus control.

\section{Goal Setting, Intrinsic Appeals, and Learners' Attitudes}

Adults learn best when they feel that they are participating in setting up educational goals for themselves. Therefore, establishing realistic learner goals is mandatory. Furthermore, learners' educational goals should be set and pursued in a meaningful context. Teachers should strive to draw on the learners' experiences by linking them to the new knowledge and skills they are acquiring. ESL learning fosters the freedom to move across cultures rather than being bound to strict norms. It helps in obtaining a negotiation of choices. The learners should be challenged with difficult but attainable tasks (Rance-Roney, 1995). Research suggests that if we set higher goals for an ESL learner, doing so will lead the learner to higher performance by activating effort. In other 
words, goal setting influences effort, which in turn influences performance. Gardner (1985) propounds that desire to learn a language and satisfaction must co-exist with effort. These concepts can be visualized as "valence", and they refer to the value of an outcome. If language students do not perceive value in their performance, then their motivation will be lowered (Oxford \& Shearin, 1994). Individuals who accept specific and challenging goals outperform individuals with nonspecific and manageable goals. If the learning activities, say reading, problem-solving, and presentations, are challenging, stimulating and effectively positive, the learner will be motivated to continue paying attention and being actively involved in what is being presented in the classroom. Vygotsky's (1978) classic work implies that SL learning goals must be based on learners' needs and interests for motivation to occur, and the input from the teacher must be both relevant and demanding. If these stipulations are not met, progress through the zone of proximal development will be stunted. Rinne (1998) suggests that the approach of focusing on a lesson's content offers the most promising and practical means of motivating students. He proposes intrinsic appeals, which are latent in most of the subjects. Each appeal has the power to attract and hold students' attention, but different interests "appeal" to different students. What captures one student's attention might not affect another, and what appeals to one student today might not have the same effect tomorrow. The effective teacher needs to present numerous examples in any given lesson. The more diverse scenarios shared, the more likely that every student in the class will find something intrinsically satisfying in the lesson. To Rinne (1998), appeal lies within the subject matter, whereas motivation is the impulse, the will, the drive, the feeling within the student. Intrinsic motivation is not synonymous with "fun", motivated students do not necessarily "enjoy" their learning, but they do feel involved and compelled to work at their learning tasks. The intrinsic appeals include novelty, surprise, anticipation, security, challenge, completion, application, feedback identification, possession, belonging, achievement, and production. Novelty is the opposite of routine. In a surprise, students consider an unexpected turn of events. Appeals to anticipation prompt curiosity and suspense. Security is the reassurance of familiarity, safety, and efficacy. Intrinsic challenges include a problem that begs to be solved, a question that resists an answer, an obstacle that needs to be overcome, or a goal that might (or might not) be reached. Completion refers to connecting or relating one part of the lesson to another part of the same lesson. Application demands using the skills learned in the lesson to be used somewhere outside the lesson. Feedback allows a student to see the results of engagement with the content immediately. These include possession, belonging, achievement, and projection. It is interesting to note that intrinsic motivation for achievement is usually content-oriented. If prizes are added to the lesson, intrinsic motivation is likely to disappear. Glasser (1986) has used nine intrinsic motivation appeals for teaching 200 spelling words in a lesson. To improve students' performance, apart from these nine points, winning is also a significant appeal that can be applied through competition. The appeal-laden lessons have a high potential to attract every student to stay focused on the lesson. Gardner and Masgoret (1999) view motivation to be in a causal relationship with language anxiety such that high levels of motivation result in low levels of anxiety. Gardner et al. (2004) suggest the need to motivate students and reduce language anxiety by applying appropriate teaching strategies that could affect attitudes towards the learning situation, which in turn can be moderated by the individual's integrative attitude.

\subsection{New Developments}

New developments in educational psychology emphasize the central importance of the learners and their attitudes towards acquiring new information. Second language learners are seen to have different needs and interests, which surely would have a significant influence on their subject mastery. This argument leans in support of the development of courses in which relevance to the learners' needs and interests is paramount. The standard way of achieving this relevance is to quote and use excerpts from the learners' specialty areas. The assumption underlying this approach is that the precise relevance of the English course to their needs would improve the learners' motivation and thereby make learning better and faster. Cloud (1998) emphasizes the need for considering the aptitude, attitude, and motivation of the learners. She considers the learning style and strategic planning, cognition, and motivation to be of paramount importance. Considering a sizeable number of factors in planning SL instruction will lead to the success of an ESL program. Conteh-Morgan (2002) is of the view that all the teachers should be aware of cross-cultural communication, first and second language acquisition theories, teaching methods, and material development. The curriculum guide should be based on linguistic theory rather than on teaching methodology. This training manual develops a sense of continuity that results in giving students a sense of purpose and direction. Adhering to linguistic theory is of utmost importance as it influences learners' expectations, motivation, and performance (Nolan, 2001).

\section{English Language, Culture, and Community}

Knowing the English language with its idiosyncrasies is an excellent advantage in participating in and adjusting 
to a new culture. Assimilating others' culture contributes positively to a learner's development of English language learning. Early socio-cultural experiences have a more significant influence on a learner's current cultural attitude, motivation to learn ESL, and understanding of language acquisition. Research demonstrates that context has a direct effect on motivation that, in turn, has a direct effect on post instruction language proficiency, whereas the mode of instruction has direct effects on both motivations and post-instruction language proficiency, according to Buttaro (2001). Motivation is conceptualized as a composite of the individual's desire to learn the language. It is also responsible for some of the individual differences in SL acquisition. Smit and Dalton (2000) postulate that developing a positive attitude towards the English language community leads to enhancing intrinsic motivation. In their research, the Austrian students of English revealed a high degree of motivation to improve their pronunciation of English with the ultimate goal of near-native language competency. They volunteered extrinsic and intrinsic motives in support of achieving this aim, as well as a general appreciation of the pronunciation course offered to them. Firstly, the students fulfilled precondition for pronunciation learning. Secondly, their anxiety decreased from Test 1 to Test 2, showing a positive attitude towards classes. Thirdly, the students recognized the relevance and significance of the pronunciation classes. Fourthly, being self-dependant and self-reliant, the students acquired a good grasp of pronunciation learning. Investment in the target language is complementary to motivation theories as it explains the complicated relationship between the learner and the social world. ESL fosters the recreation of individual identity through discourse (Ulman, 1997).

The basic premise of the socio-educational model of second language acquisition gives paramount importance to the learners' concept of identity and identification with the other language community. The learner wants to be a part of the target language community. That is why the concept of intrinsic motivation plays a pivotal role in second language learning and teaching (Gardner et al., 2004). In his Acculturation Model, Schumann (1978) suggests that acquiring a Second Language is one aspect of acculturation that determines the degree of success. When an individual chooses to acculturate and experiences success, the motivation to learn the SL increases (Berman, 1998). Motivation to learn an SL is grounded in positive attitudes towards the SL community. It involves a conviction to communicate with and become similar to the valued members of that community (Clement, Dornyei, \& Noels, 1994). They offer as an example that individuals whose interest in learning English includes socio-culture and non-professional reasons possess the highest degree of desired proficiency. They aim to master the English language. Also, socio-culturally-based orientations seem to be essential for motivation. Socio-cultural orientation includes intended contact with members of the SL group.

\section{ESL Classroom Dynamics with a Kaleidoscopic Instructor}

In order to motivate one's students, an instructor can play a pivotal role. Teachers need to create an environment that fosters self-esteem and interest in learning. Stimulating, supportive, and meaningful teaching methods are crucial for academic success. Considering learners as resources helps them in sharing their knowledge and expertise in the classroom. In designing the activities, the teacher should plan and execute insightful, creative, and innovative activities that provide an opportunity for the learners to generate the language they have acquired. Above all, the teacher should create a supportive emotional environment where students can feel at ease and polish language skills. A pattern for this constant motivation may continue throughout a student's life (Buttaro, 2001).

Situation-specific factors significantly contribute to SL motivation in a foreign language classroom for which group dynamics may be an issue. Therefore, current language teaching methodologies should aim at developing learners' competence through communicative events, as if they are participating in a social milieu, as an application of the socio-psychological constructs of group dynamics prove to be useful in describing the target language classroom environment (Clement et al., 1994). Thus, the teacher can make the SL classroom a welcoming, inviting, positive place where psychological needs are met and where language anxiety is kept to a minimum (Oxford \& Shearin, 1994). Kellogg (2001) emphasizes good advising, along with linking students' outside interests to their academic pursuits. He further advocates collegial work, extracurricular activities, forming study groups, and fostering diversity. The ideal learning environment should have a small student-teacher-ratio, coupled with the teacher's enthusiasm, patience, warm reception, and personalized acceptance and concern for each student (Helms, 1995). ESL program directors should look for idealism and ingenuity in prospective teachers (Pollak \& Farris, 1992). According to Piaget, as cited by Woolfolk (2006), language development, whether it is a second or foreign language, deserves and requires a stimulating atmosphere; without this kind of environment, the individual's inborn, motivated quest for cognitive growth may be hindered. Therefore, innovative, communicative second/foreign language classrooms offer a quantum leap in terms of richness and variety of speech stimulation. By their very nature, SL environments are much better at providing exceptionally rich input for learners, and foreign language teachers should, whenever possible, draw 
ideas, materials, and inspiration from the second language setting. Williams (2001) suggests drawing attention to cognates, scaffolding academic development with structure learning activities, waiting plenty of time for a response, encouraging students to substitute words from their native language, and establishing a risk-free environment as contributing factors for creating intrinsic motivation in ESL students.

\subsection{Creating Opportunities}

An ESL teacher should create opportunities in the classroom where the student seems to dominate all practice opportunities, volunteers more answers, is precise in his/her responses, and should be satisfied and excited by his/her participation. The classroom atmosphere is related to student involvement. A stimulating, reassuring atmosphere helps in promoting students' self-confidence and lessens anxiety. Being verbally active in class shows one's ability to use the English language, which then may be transferred outside the classroom (Clement et al., 1994). Cohen and Lotan, Fernandez-Borillas and Morrison, and Ogbu (as cited by Buttaro, 2001) suggest that, since adult learners bring their native culture, information and experiences into the classroom, intellectual refinement of learning opens up many avenues of communication with others. A learner-centered context that emphasizes the affective domain with the idea that students bring an experience and knowledge base to a classroom has been seen as an effective strategy for language pedagogy (Conteh-Morgan, 2002).

\subsection{Creating Innovations}

The ability to deal with a variety of students' demands and challenges reflects how influential an ESL instructor can be. An awareness regarding students' differences in the use of target language, sociability, needs, and wants must be in line with a teachers' scholastic explanation of the content subject. The daily lessons should be explained by considering pupils' thinking and behavior that ultimately provide teachers an opportunity to create innovative examples and explanations as and when needed in the classroom (Hassan, Davidson, \& Marshall, 2009).

\subsection{Motivation}

Though motivation is primarily a responsibility of the learners, teachers' endeavors to motivate students should be laden with constructive, positive feedback (Nunan \& Lamb, 1996). Examples may include passing out decals, stickers of sports teams, or awarding points for free snacks. A teacher's liberation attempt in the classroom can place the adults in charge of their assignments and hence may facilitate learning. Teachers act as co-learners having different kinds of experiences and resources to access. If ESL programs are conceived as learner-centered, then some individuals may not be intrinsically motivated to study English, but a few schooled as open thinkers would instead take active participation in all walks of life. Buttaro (2001) revealed that the eight Hispanic women who participated in his case study reported that the significant factor for fostering the study of ESL is enthusiasm and encouragement from their teachers. The teacher's caring about students also leaves an impact on the learners. If a teacher tutors the students on an individual basis, then the learners are more inclined to grasp pronunciation correctly. Working for enhancing students' vocabulary would lead to a significant rise in their self-esteem. The participants adduced that their habits were a significant effect on their culture and tradition. As they started mingling with Americans, they started assimilating into American culture and language. It provided an impetus for academic involvement. Therefore, considering the cultural and social needs of the families helped in understanding the broader literacy demands on the household. The participants further added that field trips, traveling by train, and studying maps were all helpful in retaining what they had learned as they associated and shared this information with family members. They considered helping their children with homework, answering the phone, reading the mail, and conversing with English-speaking professionals as an academic challenge. These challenges helped them to improve their language literacy. The essential strategies that inspired the participants included drawing pictures, memorizing words, listening to tapes, singing songs, taking pictures for creating biographies, and reading children's literature. These activities allowed the students to generate language that they had already acquired as the activities themselves were supporting and nurturing.

\subsection{Community-Based Literacy Programs}

August and Hakata (1997) believe that ESL programs should emphasize community-based literacy programs where children's motivation to succeed in schools is a reflection of their mother's educational achievement. If parents prepare their children to read adolescent books at home, the children would have a higher goal to achieve.

The discovery of new concepts in ESL learning is associated with planned opportunities. Collaborative learning through pair work and group work can help provide authentic motivational opportunities. It also offers a wide range of language from the teachers as well as from peers at different points in their language development and 
can be used to engage students in discussions of academic content. For example, using content-based poetry to introduce concepts allows students and individuals to incorporate singing and to chant in lessons. Poetry serves here as a scaffolding for introducing language learning (Hadaway, Vardell, \& Young, 2001). Using the instructional conversation format leads to the ownership of the dialogues. In this way, students' increased significance of what is being said increases motivation (Williams, 2001).

\section{Expertise in Reading Skill: Small Group Interaction}

The practical implications for developing expertise in a reading suggest creating learning environments where students read with understanding, feel successful, learn strategies to improve reading, monitor their reading, and are motivated to practice. To develop expertise in reading, the language instructors and learners have to show particular interest in repeated reading as an instructional strategy. This rehearsal strategy provides substantial practice in reading the text and allows novices to feel like experts. Research on repeated reading has documented enhanced fluency, vocabulary, reading comprehension, and motivation, and confidence. An ESL teacher should furnish access to multilevel books, provide opportunities for practice with the simple text, give freedom in the choice of books, appreciate small group shared reading, and incorporate social interaction by providing a reading model. It helps develop substantial growth in the reading abilities of a Second Language learner. Results from comprehension and fluency assessments as well as teacher, parent, and student questionnaires and interviews revealed enhanced comprehension and motivation for ESL students in book-rich classrooms both with and without a home component. Rereading books at home with the help of audiotapes increases accuracy and fluency, as has been shown by the research findings (Koskinen et al., 1999). In this way, students not only read more but also develop confidence and independence in learning activities.

\subsection{Book Introduction}

The impact of the book introductions on students' ability to understand the text, and their motivation to read is impressive. Beginning with an overview of a story helps students make connections to their prior knowledge, including links to other stories they have heard or read. Modeling the use of language structures and vocabulary helps students prepare for independent rereading. This practice encourages students to participate more actively in shared reading and to take on more readily the task of independent reading. The participatory nature of the introductions in small group settings allows students to have more opportunities to interact with and become engaged in the text. Small-Group interaction increases students' comprehension. Increasing interaction also enhances the motivation for reading. Teachers most frequently mention the benefits of choice and its impact on both motivation and students' concepts of themselves as readers. Interviews with students have indicated that they are motivated to participate in home reading, with $63 \%$ reporting that they read at homes almost every day (Koskinen et al., 1999). Inexpensive backpacks, decorated with a beautiful logo, provide a motivating and convenient way to transport literacy materials. They not only facilitate the return of materials from home but also help students remember to read daily. After all, intrinsic motivation correlates positively with the end-of-training speaking and reading proficiencies (Ehrman, 1996). Struggling readers and adult learners having motivational problems can be aroused by the content organization and traditional themes such as sports, mysteries, parenting hints, science fiction (Schroeder-Davis, 1996). Teachers understand that reading abilities are more likely to emerge when students are engaged in reading as a recreational activity rather than pursuing class assignments. Instructors should consider collaborative learning groups. They should teach all aspects in an integrated way by fostering receptive and productive use of language by establishing a communicative approach (Conteh-Morgan, 2002).

\subsection{Dialogue Writing}

Writing is a challenging cognitive task, for an ESL learner. Holmes and Moulton (1997) are of the view that dialogue writing enhances thinking skills and, as a consequence, builds students' motivation to write. By responding to the content of students' writing and not correcting their errors, teachers can "minimize fear, nervousness, and self-consciousness" by controlling affective variables that impact the writers' motivation (Holmes \& Moulton, 1997, p. 620). The students' freedom to write about what is essential is another motivating factor. Without struggling to discover a topic that is pleasing to the teacher, students are free to explore issues of personal significance, playing with language along the way. Writing increases self-esteem, and peer correction enables the learners to analyze the similarities and differences between mother tongue and target language (Buttaro, 2001).

\section{Should a Reward Always Be There?}

Research has revealed certain particular situations under which reward can have either no impact or a positive impact on intrinsic motivation and creativity. Such effects have been termed motivational synergy, and it has 
been suggested that they fit well with Deci and Ryan's (1985) cognitive evaluation theory. In one series of studies designed to investigate this phenomenon, researchers were successful at "immunizing" elementary school students against the usually deleterious effects of expected reward. These children, who were helped to focus on intrinsic motivation and were taught specific techniques for viewing external incentives as secondary to their interest and learning, we can maintain baseline levels of intrinsic motivation and creativity and sometimes even showed increases in innovative thought and action when promised a reward for task participation. Moreover, the conditions under which these effects occur are not highly restricted (Hennessey \& Amabile, 1998).

Intrinsic motivation may be fun, but at the same time, it is intense, sustained in concentration and involvement. The question is not whether students should learn to endure long hours of homework; the question, instead, is how teachers can motivate students to practice what appears to be tedious lessons. Even in rigorous and unpleasant military training, drill instructors use intrinsic motivation, i.e., "the pride of the corps", "the right stuff". All are intrinsic persuasive appeals that have no direct links to pay rates or gold medals. In many areas of life, appeals to intrinsic motivation inspire people to work long and hard; intrinsic appeal works in schools because students generally react the way all people do (Rinne, 1998).

\section{Limitations}

We must not forget that certain variables such as motivation, coordination of mental processes, integrativeness, and instrumental orientations could change the process of second language acquisition. However, this transformation is not the same as initial speed mastery in magnitude. Some of the variables could sustain modification more than others Similarly, sometimes students develop or show a general tendency to be motivated to attain some goal, and hence a particular state of motivation is aroused at any given time. Succinctly, a change in motivation and anxiety is also possible over some time. Gardner et al. (2004) observed very little change in the attitude, motivation, or anxiety of the high-grade achievers as they tend to maintain exceptional levels of motivation and low levels of anxiety over time. Consequently, they reached a comfort level, where less effort and enthusiasm worked for language learning. It is noteworthy that intrinsic motivation strategies may not apply to all sections and segments of a course of study. Instructors use strategies that seem adequate to them to relate to select student populations to boost learners' motivation. It is also important to note that the strategies applied to one subject may not be applied to all. Further, whether a successful application could have desired results on learners' motivation is still open for discussion.

\section{Conclusion/Concluding Remarks}

Learning English as a Second Language is a dynamic process that is influenced by numerous affective variables, in which motivation remains prominent. Effective teaching demands that the instructor should understand the pivotal role played by motivation in language learning. By incorporating the motivational strategies as mentioned above, the instructors can discern an augmented intrinsic motivation that is amenable to learners' satisfaction in studies. It is the view of the principal investigator that the application of motivational strategies in the contemporary classroom setting will open different avenues of intended discovery and serendipity in the Arab World where teaching and learning of ESL are emerging at a rapid pace. More empirical research on the effects, appropriation, and amelioration of intrinsic motivation on other subjects should be conducted

\section{Acknowledgments}

The authors acknowledge with thanks for the technical support provided by Deanship of Scientific Research (DSR) King Abdulaziz University, Jeddah, KSA.

\section{References}

August, D., \& Hakata, K. (1997). Improving school for language-minority children: A research agenda. Washington D. C.: National Academy Press.

Bandura, A. (1997). Self-efficacy: Toward a unifying theory of behavioral change. Psychological Review, 84, 191-215. https://doi.org/10.1037/0033-295X.84.2.191

Belmerchi, F., \& Hummel, K. (1998). Orientations and motivation in the acquisition of English as a second language among high school students in Quebec City. Language Learning, 48, 219-244. https://doi.org/10.1111/1467-9922.00040

Benware, C., \& Deci, E. L. (1984). Quality of learning with an active versus passive motivational set. American Educational Research Journal, 21, 755-765. https://doi.org/10.3102/00028312021004755

Berman, M. (1998). Russian Immigrants in the ESL classroom. Success, Motivation, and Acculturation. ESL Magazine, 1, 28-30. 
Buttaro, L. (2001). Understanding Adult ESL Learners: Multiple dimensions of learning and adjustments among Hispanic women. Adult Basic Education, 11.

Clement, R. B., Dornyei, Z., \& Noels, K., (1994). Motivation self-confidence and group cohesion in the foreign language classroom. Language learning, 44, 417-488. https://doi.org/10.1111/j.1467-1770.1994.tb01113.x

Clement, R. B., \& Kruidenier, G. (1985). Aptitude, attitude, and motivation in second language proficiency: A test of Clement's model. Journal of Language and Social Psychology, 4, 21-37. https://doi.org/10.1177/0261927X8500400102

Cloud, N. (1998). ESL in special education. ERIC Digest.

Conteh-Morgan, M. (2002). Connecting the Dots: Limited English Proficiency, Second Language Learning Theories and Information Literacy Instruction. Journal of Academic Librarianship, 28, 191-197. https://doi.org/10.1016/S0099-1333(02)00282-3

Deci, E. L., \& Ryan, R. M. (1985). Intrinsic motivation and self-determination in human behavior. New York: Plenum. https://doi.org/10.1007/978-1-4899-2271-7

Deci, E., Vallerand, R., Pelletier, L., \& Ryan, R. (1991). Motivation and Education: the self-Determination perspective. Educational Psychologist, 26, 325-346. https://doi.org/10.1207/s15326985ep2603\&4_6

Ehrman, M. E. (1996). Understanding Second Language Learning Difficulties. CA: Sage, Thousand Oaks.

Gardner, R. C. (1985). Social psychology and second language learning: The roles of attitudes and motivation. London: Arnold.

Gardner, R. C., \& Masgoret, A. (1999). Home Background Characteristics and Second Language Learning. Journal of Language and Social Psychology, 18, 419-438. https://doi.org/10.1177/0261927X99018004004

Gardner, R. C., Masgoret, A. M., Tennant, J., \& Mihic, L. (2004). Integrative motivation: Changes during a year-long intermediate-level language course. Language Learning, 54, 1-34. https://doi.org/10.1111/j.1467-9922.2004.00247.x

Gardner, R. C., Tremblay, P. F., \& Masgoret, A. M. (1997). Towards a full model of second language learning: An empirical investigation. Modern Language Journal, 81, 344-362. https://doi.org/10.1111/j.1540-4781.1997.tb05495.x

Glasser, W. (1986). Control Theory in the Classroom. New York: Harper \& Row.

Gottfried, A. E. (1990). Academic intrinsic motivation in young elementary school children. Journal of Educational Psychology, 82, 525-538. https://doi.org/10.1037/0022-0663.82.3.525

Gray, M. (2001). New Mexico Business Welcome Volunteers Who Teach English to Employees. Albuquerque Journal.

Gronlnick, W. S., \& Ryan, R. M. (1987). Autonomy in Children's Learning: An experimental and individual difference investigation. Journal of Personality and Social Psychology, 52, 890-898. https://doi.org/10.1037/0022-3514.52.5.890

Hadaway, N., Vardell, S., \& Young, T. (2001). Scaffolding oral language development through poetry for students learning English. Reading Teacher, 54, 796-807.

Hassan, H., Davidson, B., \& Marshall, R. (2009). A motivating instructor. National Form of Educational Administration and Supervision Journal, 26, 67-77.

Helms, M. C. (1995). Reaching out to the International Students through Bibliographic Instruction. The Reference Librarian, 24(50-51), 295-307. https://doi.org/10.1300/J120v24n51_28

Hennessey, B., \& Amabile, T. (1998). Reward intrinsic motivation and creativity. American Psychologist, 53, 647-675. https://doi.org/10.1037/0003-066X.53.6.674

Holmes, V. L., \& Moulton, M. R. (1997). Dialogue journals as an ESL learning strategy. Journal of Adolescent \& Adult Literacy, 40, 616-622.

Jones, K. (1989). Running or stumbling through stimulations. Simulation/Games for Learning, 19(4), 160-167.

Kellogg, A. (2001). Harvard Professor Becomes a Guru on Helping Students. Chronicle of Higher Education, 47, 33.

Koskinen, P., Blum, I., Bisson, S., Philips, S., Creamer, T., \& Baker, T. (1999). Shared reading books and audio-tapes: supporting diverse students in school and at home. Reading Teacher, 52, 430-445. 
Kyriacou, C., \& Kobori, M. (1998). Motivation to learn and teach English in Slovenia. Educational Studies, 24, 345-352. https://doi.org/10.1080/0305569980240307

Noels, K. A., \& Pelletier, L. G. (2000). Why are you learning a Second Language? Motivational orientations and self- determination theory. Language Learning, 50. https://doi.org/10.1111/0023-8333.00111

Nolan, R. E. (2001). The power of theory in the administration of ESL programs. Adult Basic Education, II.

Nunan, D., \& Lamb, C. (1996). The Self-directed Teacher (4th ed.). Cambridge: CUP.

Oxford, R., \& Shearin, J. (1994). Language learning motivation: Expanding the theoretical framework. Modern Language Journal, 78, 12-28. https://doi.org/10.1111/j.1540-4781.1994.tb02011.x

Payne, M. (2000). On the Job English Classes for Pay Off at Elk Grove, Calif., Firm. The Sacramento Bee.

Pollak, J. P., \& Farris, R. A. (1992). The motivation for teaching: Implications for Recruitment. Education, 112, 423-326.

Rance-Roney, J. (1995). Transiting Adult ESL Learners to Academic programs. ERIC Digest.

Rinne, C. H. (1998). Motivating students is a percentage game. Phi Delta Kappan, 79.

Ryan, R., \& Deci, E. (2000). Self-determination theory and the facilitation of intrinsic motivation, social development, and well-being. American Psychologist, 55, 68-78. https://doi.org/10.1037/0003-066X.55.1.68

Schroeder-Davis, S. (1996). For struggling readers. School Library Journal, 42, 42.

Schumann, J. H. (1978). The acculturation model for second language acquisition. In R. Gingras (Ed.), Second language acquisition, and foreign language teaching (pp. 27-50). Arlington, VA: Center for Applied Linguistics.

Smit, U., \& Dalton. C. (2000). Motivational Patterns in Advanced EFL Pronunciation Learners. IRAL: International Review of Applied Linguistics in Language Teaching, 38(3-4). https://doi.org/10.1515/iral.2000.38.3-4.229

Taylor, L., \& Adelman, H. (1999). Personalizing classroom instruction to account for motivational and developmental differences. Reading \& Writing Quarterly, 15, 255-277. https://doi.org/10.1080/105735699278107

Tremblay, P., \& Gardner, R. (1995). Expanding the motivation construct in language learning. The Modern Language Journal, 79, 505-520. https://doi.org/10.2307/330002

Ulman, C. (1997). Social Identity and Adult ESL Classroom. ERIC Digest.

Vallerand, R. J., \& Pelletier, L. G. (1993). On the assessment of intrinsic, extrinsic, and motivation in Education: Evidence on the concurrent and construct validity of the Academic Motivation Scale. Educational \& Psychology Measurement, 53, 159. https://doi.org/10.1177/0013164493053001018

Vygotsky, L. S. (1978). Mind in society: The development of higher psychological processes. Cambridge, MA: Harvard University Press.

Wan, G. (2001). The learning experience of Chinese students in American Universities: A cross-cultural perspective. College Student Journal, 35.

Williams, J. A. (2001). Classroom Conversations: Opportunities to learn for ESL students in mainstream classrooms. Reading Teacher, 54, 750-758.

Woolfolk, A. (2006). Educational Psychology (9th ed.). MA: Allyn and Bacon.

Yule, G. (1996). The study of Language. Cambridge University Press: Cambridge.

\section{Copyrights}

Copyright for this article is retained by the author, with first publication rights granted to the journal.

This is an open-access article distributed under the terms and conditions of the Creative Commons Attribution license (http://creativecommons.org/licenses/by/4.0/). 